\title{
103. Vertigo in Posttraumatic Syndrome
}

(The second report)

T. OKusa, K. Nishigaido, K. IKeda, M. Ebara, K. AKashi, Y. Machida, Y. Kushida, S. NaKano and K. Michishita

2nd Clinic of Surgery, School of Medicine, Toho University

Most of the patients who sustained minor or severe injuries to the head complained of vertigo, which might cause the disturbances of central nervous system, vestibular disfunction and automatic nervous unbalance.

The patients with complaint of Vertigo after head injuries were observed in the investigations of vestibular function comparing with C.A.G., E.E.G. and cerebrospinal fluid findings.

The materials for this studies were the patients with vertigo and normal adults.

The findings of E.E.G., vestibular disfunction and cerebrospinal fluid did not always agree.

\section{Relation of the Vertigo or Dizziness to the Audiogram Pattern after Cerebral Concussion or Contusion}

\author{
Tsuneo OHNo \\ Dept. of Neurosurgery, Kanto Rosai Hospital \\ Michiya OKамото \\ Dept. of Otol. Rhin. Laryng., Kanto Rosai Hospital
}

We have studied the classification of the post-traumatic audiogram into normal, peripheral (cochlear) and central patterns, except for conduction deafness.

We can demonstrate 3 cases with the interesting relationship between those patterns and the findings of vestibular function test in Fig. 1, 2, and 3. It seems that these cases may suggest the correlation of the central auditory disturbance and the central vestibular disfunction.

We had 343 consecutive cases after head injury with no evidence of direct labyrinthine destruction or disease. Relation of audiometric findings of these 343 cases to their complaints about vertigo and/or dizziness is represented in Table 1. The coefficient of the correlation between the 